\title{
Article \\ Distress and Resilience in Resettled Refugees of War: Implications for Screening
}

\author{
Michael Hollifield ${ }^{1,2,3, *}$, Eric C. Toolson ${ }^{4}$, Sasha Verbillis-Kolp ${ }^{5,6} \oplus^{\circ}$, Beth Farmer ${ }^{7}$, Junko Yamazaki ${ }^{8}$, \\ Tsegaba Woldehaimanot ${ }^{8}$ and Annette Holland ${ }^{9}$ \\ 1 VA Long Beach Healthcare System, Long Beach, CA 90822, USA \\ 2 Department of Psychiatry and Behavioral Sciences, The George Washington University School of Medicine, \\ Washington, DC 20052, USA \\ 3 War Survivors Institute, 5318 2nd Street, \#703, Long Beach, CA, 90803, USA \\ 4 Department of Biology, The University of New Mexico, Albuquerque, NM 87131, USA; toolson@unm.edu \\ 5 Consultant, 3630 N. Winchell St., Portland, OR 97217, USA; sverbilliskolp@gmail.com \\ 6 Portland State University School of Social Work, Academic Student Recreation Center, Ste. 600, \\ 1800 SW 6th Ave., Portland, OR 97201, USA \\ 7 International Rescue Committee, 1200 S. 192nd St., SeaTac, WA 98148, USA; Elizabeth.Farmer@rescue.org \\ 8 Asian Counseling and Referral Service, Seattle, WA 98144, USA; junkoy@acrs.org (J.Y.); \\ tsegaba@u.washington.edu (T.W.) \\ 9 Public Health Seattle \& King County, Seattle, WA 98121, USA; Annette.Holland@kingcounty.gov \\ * Correspondence: michael.hollifield@va.gov
}

check for updates

Citation: Hollifield, M.; Toolson, E.C.; Verbillis-Kolp, S.; Farmer, B. Yamazaki, J.; Woldehaimanot, T.; Holland, A. Distress and Resilience in Resettled Refugees of War: Implications for Screening. Int. J. Environ. Res. Public Health 2021, 18, 1238. https://doi.org/10.3390/ ijerph18031238

Received: 1 December 2020

Accepted: 27 January 2021

Published: 30 January 202

Publisher's Note: MDPI stays neutral with regard to jurisdictional claims in published maps and institutional affiliations.

Copyright: (c) 2021 by the authors. Licensee MDPI, Basel, Switzerland. This article is an open access article distributed under the terms and conditions of the Creative Commons Attribution (CC BY) license (https:// creativecommons.org/licenses/by/ $4.0 /$ )
Abstract: There is little work published about predictors of specific trajectory types of distress in refugees of war during early resettlement in a host country. Data about distress (Refugee Health Screener-15 (RHS-15)) and possible predictors of distress were collected at the domestic medical examination (T1) within 90 days of arrival and the civil surgeon examination (T2) 11-16 months after T1 for refugee groups from three countries (COU). Descriptive, correlative, analyses of variance, and regression techniques were used to determine trajectory type and their predictors. A higher percentage $(7.3 \%)$ were distressed at $\mathrm{T} 2$ than at $\mathrm{T} 1$. By group, the Bhutanese became more distressed, the Burmese became less distressed, and Iraqi's continued to have high distress. A regression model showed gender, loss, post-migration stress, and self-efficacy to be significant predictors of trajectory type $\left(R^{2}=0.46\right)$. When the T1 RHS-15 score was added to the model, observed variance increased $\left(\mathrm{R}^{2}=0.53\right)$ and T1 RHS score accounted for the majority of variance $(r=0.64, p<0.001)$, with post-migration stress accounting for markedly less $(\beta=0.19, p=0.03)$. Loss and self-efficacy became less significant. Loss was, however, a strong predictor of delayed and chronic distress trajectory type. These data suggest that screening for distress should occur at least twice during resettlement to detect those with initial distress and those with delayed distress. Screening should be coupled with identifying other social determinants of health and a comprehensive assessment to determine the need for intervention for secondary prevention (i.e., reducing delayed distress) and treatment (reducing chronic distress).

Keywords: health trajectory; refugee health; war; emotional distress; screening

\section{Introduction}

Worldwide, seventy-nine million persons are forcibly displaced from their homes. Twenty-six million are refugees, $85 \%$ of whom are hosted in developing countries. From 1975 to 2017 more than three million refugees were invited to resettle in the United States [1]. Cross-sectional studies show that the majority of refugees experience multiple distressing symptoms, and a significant minority suffer from diagnostic-level psychiatric disorders [2-10], which are associated with stressful war- and migration-related events in a dosedependent manner [7,11-13]. Furthermore, the overall health of refugees is compromised by the known association of chronic stress on health, in particular cardiovascular [14-23] 
and inflammatory $[17,18,24-26]$ symptoms and disease [27]. Refugees experience significant health disparities over time due to an initially high health burden on arrival coupled with poor access to and engagement in general and mental health services [28]. Findings of Wong and colleagues epitomized this poor health trajectory over time by showing the unusually poor health status of Cambodian refugees two decades after resettlement in the U.S. [29].

Because incoming refugees have significant distress coupled with a high risk for poor overall health, screening for distress and referring for care during resettlement is warranted. Mental health screening at the domestic medical examination is supported by the Centers for Disease Control [30]. However, there are significant barriers to routine screening, including system and refugee factors [31] and a lack of knowledge about the clinical- and cost-effectiveness of screening and appropriate timing during resettlement. There are studies about distressing symptoms over time during the resettlement period that might inform screening protocols. Lie found that, over a 3-year post-resettlement period in Norway, anxiety and depression levels were unchanged, posttraumatic stress (PTSD) levels increased, and pre- and post-resettlement stressors were risk factors for worsening health status [32]. Ryan and colleagues showed similar levels of distress over one year in asylum-seekers in Ireland, mitigated by improved legal status [33]. Likewise, Steel and colleagues found similar rates over time, but rates were lower in asylees with permanent vs. temporary visas [34]. A longitudinal study in Sweden and Kosovo also showed a two-fold increase in PTSD symptom prevalence in refugees from Kosovo in an 18-month post-settlement period [35]. Another 3-year longitudinal study of Bosnian refugees determined that PTSD and depression symptoms persist during the resettlement period [36]. Kaltenbach and colleagues recently reported on a sample of refugees and asylum seekers from 7 regions, finding no change in distress or symptoms over a one-year period on a population basis and no change in the majority of individuals [37]. Comtesse recently showed that, 11 years after the first assessments, there was differential distress between those who stayed in Sarajevo throughout the war in Bosnia and Herzegovina versus former internally displaced persons and returnees who had sought refuge in other countries during the war [38].

There are no studies, however, about specific trajectory types of distress and their predictors over time in adult refugees of war. Muller identified four trajectory types (unremarkable, reacting, adapted, and persisting) on trauma and anxiety and depression symptoms in adolescent asylum seekers [39]. The authors found a general reduction of distress over time with the most common trajectory being "unremarkable" (no distress at either time) for anxiety and depression. Baseline symptom scores were the most robust single predictor for all mental health outcomes at follow-up

We present findings from the "Pathways to Wellness: Integrating Refugee Health and Well-being" project (P2W) about the prevalence and predictors of specific distress trajectory types of newly arrived refugees from three countries. Utilizing theoretical and empirical work about symptom trajectories in populations affected by war and mass causality [40], four trajectories between two time points during the first year of resettlement were evaluated. The resistance trajectory is one where individuals never acquire significant distress symptoms. The resilience trajectory is characterized by initial symptoms followed by recovery. The chronic distress trajectory is when individuals are initially symptomatic and remain so. The final trajectory, termed the delayed distress trajectory, is characterized by the lack of initial distress followed by later distress. Our hypotheses were that trajectories of distress: (1) will vary in prevalence by country of origin (COU) and (2) are affected by trauma severity, resource loss, post-migration stress, and self-efficacy.

\section{Materials and Methods}

\subsection{Design}

A longitudinal design assessed distress at two time points: one was the domestic medical examination (DME) conducted within the first 90 days of arrival, the second was 
the civil surgeon examination (CSE) conducted between 11 and 16 months after the DME. Predictor factors (demographics, trauma, resource loss, post-migration stress, self-efficacy) were assessed at the DME.

\subsection{Sample Frame, Sampling, Setting}

The sample frame was all refugees age $\geq 14$ from three countries (Bhutan, Iraq, and Burma) speaking four languages (Nepali, Karen, Arabic, and Burmese (Karenni and Chin ethnic groups) at Public Health Seattle King County (PHSKC) for their domestic medical screening in Washington state. This sample frame was chosen as the most numerous refugee groups being resettled during the study period. Consecutive sampling of all eligible persons was conducted on pre-specified days by the P2W research coordinator at PHSKC during the DME between April 2010 and November 2010. All available refugees in this cohort were re-evaluated at the CSE between October 2010 and September 2011.

Ethical review and approvals were conducted by the Pacific Institute for Research and Evaluation and the ethics committee at Public Health Seattle and King County (PHSKC).

\subsection{Procedures and Instruments}

\subsubsection{Translation of Instruments}

Translation is complex and must be adapted for specific purposes [41]. All instruments were translated using a rigorous, iterative back-and-forth participatory consensus process with refugees from each language group. This process ensured relevant languagespecific semantics and cultural equivalence yielding accuracy and clarity of meaning across groups [13,42]. For the P2W study all scales were translated into: Burmese, Karen, Nepali and Arabic.

\subsubsection{Procedures}

Written informed consent was obtained and distress assessment conducted by the P2W research coordinator with trained interpreters at the DME. Diagnostic proxy (DP) and predictor instruments were administered by the coordinator within two weeks of the DME. Health staff at PHSKC assessed distress during the CSE, and a second P2W coordinator with interpreters administered DP instruments within 3 weeks of the CSE. Refugees were given the choice of self-administration with instructions or of interview administration to parallel clinical procedures at PHSKC.

\subsubsection{Distress: The Refugee Health Screener-15 (RHS-15)}

The RHS-15 has 13 symptom items, one coping item, and one distress thermometer (DT). The instructions for the symptom items are to "indicate the degree to which the symptom has been bothersome to you over the past month." Possible responses are: $0=$ not at all, $1=$ a little bit, $2=$ moderately, $3=$ quite a bit, and $4=$ extremely. To help address variable literacy and cultural norms for understanding scale formats, there are symbols of jars with beans in them over the possible responses, with variable amounts of beans relevant to each scale response. The coping item assesses one's beliefs about their general ability to cope with stress, and responses ranges from 0 (able to handle or cope with anything that comes your way) to 4 (unable to handle or cope with anything). The 14 symptom and coping responses are added to obtain a "total score." The DT looks like a thermometer, with a " 0 " ("no distress-things are good") at the bottom and a " 10 " (extreme distress-I feel as bad as I ever have") at the top. A "RHS-15 positive case" is defined as a total score of $\geq 12$ or a DT $\geq 5$. The RHS- 15 has shown validity to DP's in the three refugee groups sampled $[43,44]$. Follow-up research has confirmed the validity of the RHS-15 and a shorter RHS-13 in multiple refugee groups and contexts [44-47].

The RHS-15 was in development during the first stage of this study. The distress score at the DME is from an interpolated version of the RHS-15 as previously described [43]. The distress score at the CSE is from the final compatible RHS-15 version. 


\subsubsection{Diagnostic Proxy Instruments}

Very few instruments that assess symptoms as DP's have been developed for refugees [48]. None are definitive diagnostic equivalents. The Hopkins Symptom Checklist-25 (HSCL-25) is a valid indicator of anxiety and depression for the general U.S. population and for Indochinese refugees [48-51] and demonstrates transcultural validity [52,53]. Item-average scores $\geq 1.75$ predict clinically significant anxiety (ANX) and depression (DEP) on the respective scales in general U.S. and refugee samples and are considered valid DP's [49,51].

The Posttraumatic Symptom Scale-Self Report (PSS-SR) predicts PTSD diagnosis in U.S. populations [54]. Cronbach alpha is 0.91 , and one-month test-retest reliability is 0.74 . The 17 items on the scale, each scored from 0 to 3 for symptom frequency, are DSM-IV PTSD diagnostic items. The PSS-SR may be scored as continuous or a dichotomous DP. PSS-SR continuous scores and the DP are highly correlated with war-related trauma and impairment in Kurdish and Vietnamese refugees [13], and Cronbach alpha in these samples was 0.95 .

\subsubsection{Predictor Instruments}

War-related trauma was assessed with the Comprehensive Trauma Inventory-12 (CTI-12), which was adapted for this study from the Comprehensive Trauma Inventory-104 (CTI-104), a self-report instrument that reliably assesses a broad range of war-related events experienced by Kurdish and Vietnamese refugees and is a valid predictor of adverse mental health outcomes $[13,55]$. The CTI-12 consists of the 12 items that showed the strongest association with adverse mental health. Each item has 5 possible responses to reflect number of occurrences of each event: 1 = "none," 2 = "one or two times," 3 = "three to twelve times," $4=$ "thirteen to fifty times," and $5=$ " $>50$ times." Scoring may be either a sum of dichotomous values (number of events positive) or a sum of occurrences, which was used for this study. Cronbach's alpha for the current sample was 0.83 .

Resource Loss (and gains) was assessed with 31 items deemed most relevant from refugee informants from the Conservation of Resources-Evaluation (COR-E) in five domains: personal, interpersonal, material, work, and health [56]. The COR-E loss scales have been shown to be predictors of distress and PTSD in Israeli's exposed to terrorism and in American respondents after the World Trade Center attacks on 9/11 [57-59]. Respondents rated their extent of loss on a 0 to 4-point scale with the aid of a likert-type bar as guide. Item responses were summed so that higher scores reflected more loss. Cronbach's alpha is not appropriate for these items since one type of loss is not necessarily related to others.

Post-migration stress was assessed with The Post-migration Living Problems (PMLP) Scale [60-62]. The 23 items are each rated on a 5-point scale from "no problem" to "a very serious problem" with the total score being a sum of item scores. The PMLP has 5 principal components accounting for $70 \%$ of the variance: (1) refugee determination process; (2) health, welfare and asylum problems; (3) family concerns; (4) general adaptation stressors; and (5) social and cultural isolation. Confirmatory factor analysis with our data supported the validity of these indicators.

Self-efficacy was assessed with the 10-item General Self-Efficacy Scale. (e.g., "I am confident that I could deal efficiently with unexpected events") [63]. Respondents indicated how true each statement was on a 4-point scale. Summed responses yielded a total score, with higher scores reflecting higher levels of self-efficacy. Cronbach's alpha in the current sample was 0.90 .

\subsection{Data Analyses \\ 2.4.1. Definitions}

Distress was defined as a positive RHS-15 case. Time 1 (T1) was at the DME, and Time 2 (T2) at the CSE. Trajectory was defined as distress status at T2 relative to T1; see introduction for detail. The number and percent with each of the 4 trajectories by COU and gender was determined by frequency analyses. 


\subsubsection{Trajectory Predictors}

Logistic regression and analyses of variance (ANOVA) were utilized to test the hypotheses that distress trajectory will vary by COU and are affected by trauma severity, resource loss, post-migration stress, and self-efficacy. Logistic regression analyses of trajectory by COU and gender were conducted using Proc Logistic (SAS v. 9.3, SAS, Cary, NC, USA). Trajectory categories (Resistant, Resilient, Delayed, and Chronic) were treated as nominal variables and analyses were therefore based on the generalized logit model. Distress at T2 was treated as an ordinal variable with "distress" $=1$ and considered 'worse' than "non-distress $=0$, allowing use of proportional odds model. Analyses were conducted on separate and pooled data for each COU group using stepwise logistic regression with the Bayesian Information Criterion (Schwarz Criterion in SAS) being used to select the best model [64]. ANOVA was utilized to evaluate trajectory predictors by each COU and by each trajectory course.

\section{Results}

\subsection{Description of the Sample}

Figure 1 shows the sample frame, sample, and flow. During the study period PHSKC there were 493 potential participants, of which 251 were sampled at T1, and 190 were administered the diagnostic proxies (RR 76\%). Of the 251, 179 returned for evaluation at T2, and of those, 143 had been evaluated with the RHS-15 at both T1 and T2, consisting of 49 Bhutanese ( 24 female, 25 male), 53 Iraqi's ( 29 female, 24 male), and 41 Burmese (18 female and 23 male). Of the 251 sampled at T1, 77 were referred for mental health treatment, 57 accepted treatment, and 48 engaged in any treatment. Treatment outcome data were not collected. There were no clear COU differences by treatment engagement.

\subsection{Distress and Trajectories by Country of Origin}

In this sample a higher number (percentage) of refugees $(12 ; 7.3 \%)$ were distressed at T2 than at T1. Table 1 shows that COU groups differ on distress at both time points (Fisher's Exact at T1, $\mathrm{Pr} \leq \mathrm{P}=0.004$; at T2, $\mathrm{Pr} \leq \mathrm{P}=1.05 \times 10^{5}$ and that on a population basis, relative to $\mathrm{T} 1$, at $\mathrm{T} 2$ the Bhutanese became more distressed, the Burmese became less distressed, and Iraqi's continued to have similar high rates of distress. Gender within COU group did not differ significantly on distress at either time point or on trajectory type, allowing for pooled analyses.

Table 1. RHS-15 case status (Positive = above RHS-15 cutscore; Negative = below RHS-15 cutscore) by country at DME (T1) and CSE (T2).

\begin{tabular}{cccc}
\hline & \multicolumn{3}{c}{ Country of Origin } \\
\cline { 2 - 4 } & Bhutan $(\boldsymbol{n}=\mathbf{4 9 )}$ & Iraq $(\boldsymbol{n}=\mathbf{5 3})$ & Burma $(\boldsymbol{n}=\mathbf{4 1})$ \\
\hline DME Negative & 33 & 23 & 31 \\
DME Positive & $16(32.6 \%)$ & $30(56.6 \%)$ & $10(24.4 \%)$ \\
CSE Negative & 18 & 23 & 34 \\
CSE Positive & $31(63.3 \%)$ & $30(56.6 \%)$ & $7(17.1 \%)$ \\
\hline
\end{tabular}

Table 2 shows that the 4 trajectory patterns did not differ by gender within COU group (Fisher's Exact $\operatorname{Pr} \leq \mathrm{P}$, Bhutan 0.52, Iraq 0.78, Burma 0.12) and did differ by COU group (Fisher's Exact $\operatorname{Pr} \leq \mathrm{P}, 1.24 \times 10^{6}$. The Burmese showed the most resistance $(68.3 \%$ compared to $35.8 \%$ of Iraqi's and $36.7 \%$ of Bhutanese) and resilience (14.6\% compared to $7.5 \%$ of Iraqi's and $0 \%$ of Bhutanese). The Bhutanese showed the most delayed distress ( $30.6 \%$ compared to $7.5 \%$ of Iraqi's and $7.3 \%$ of Burmese), and the Iraqi's reported the most chronic distress (49.1\% compared to $32.7 \%$ of Bhutanese and $9.8 \%$ of Burmese). 


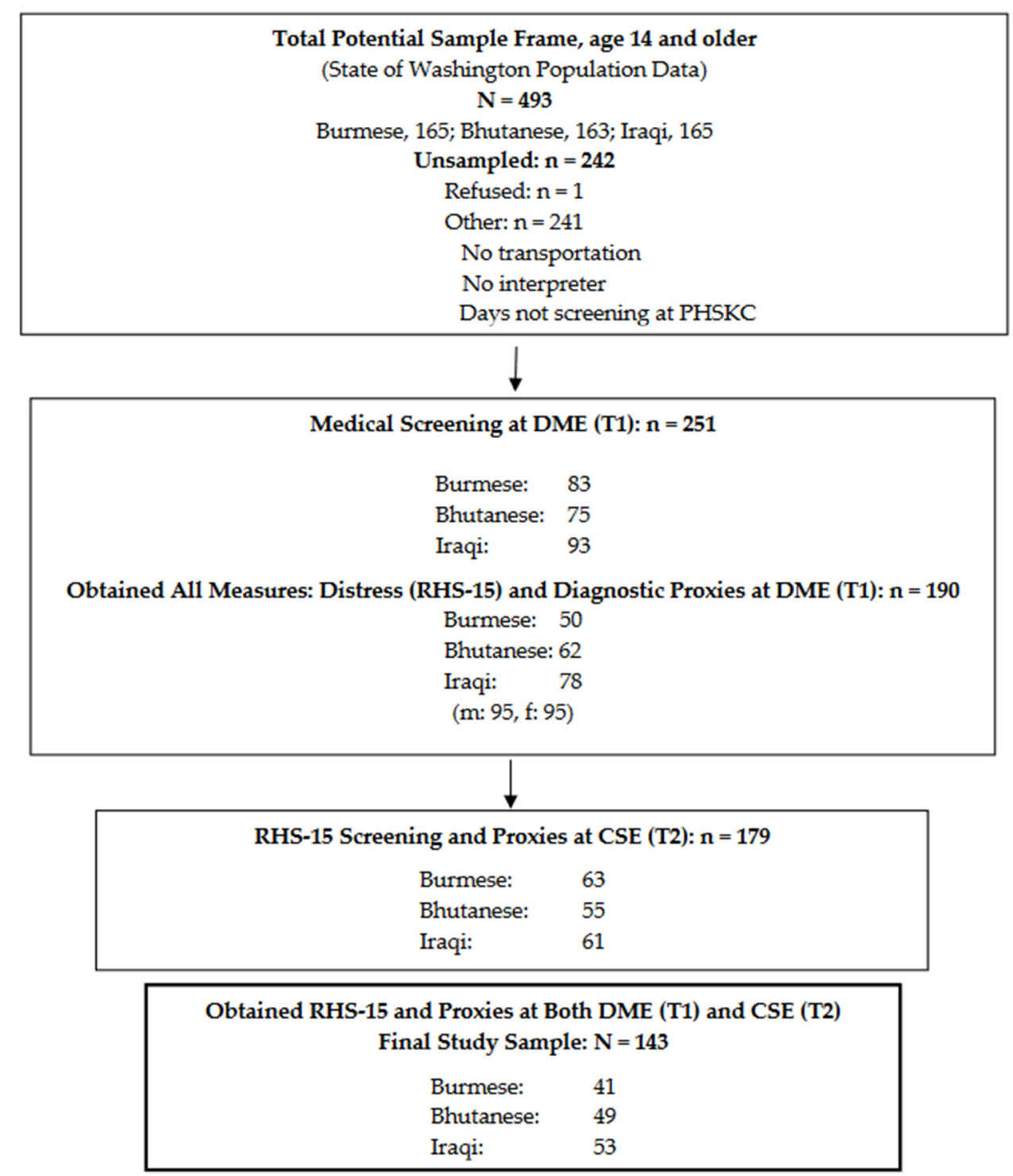

Figure 1. Sample Frame, Sample, and Subject Flow.

Table 2. Distress trajectory by country of origin and gender.

\begin{tabular}{|c|c|c|c|c|c|}
\hline & & \multicolumn{2}{|c|}{ DME Negative $(n=87)$} & \multicolumn{2}{|c|}{ DME Positive $(n=56)$} \\
\hline & & CSE Negative & CSE Positive & CSE Negative & CSE Positive \\
\hline & & $\begin{array}{c}\text { Resistant } \\
(n=65)\end{array}$ & $\begin{array}{l}\text { Delayed Distress } \\
\quad(n=22)\end{array}$ & $\begin{array}{l}\text { Resilient } \\
(n=10)\end{array}$ & $\begin{array}{l}\text { Chronic Distress } \\
\quad(n=46)\end{array}$ \\
\hline \multirow{2}{*}{$\begin{array}{l}\text { Bhutan } \\
(n=49)\end{array}$} & Female & 7 & 9 & 0 & 8 \\
\hline & Male & 11 & 6 & 0 & 8 \\
\hline \multirow{2}{*}{$\begin{array}{c}\text { Iraq } \\
(n=53)\end{array}$} & Female & 9 & 3 & 2 & 15 \\
\hline & Male & 10 & 1 & 2 & 11 \\
\hline \multirow{2}{*}{$\begin{array}{l}\text { Burma } \\
(n=41)\end{array}$} & Female & 10 & 3 & 2 & 3 \\
\hline & Male & 18 & 0 & 4 & 1 \\
\hline Total & Female & 26 & 15 & 4 & 26 \\
\hline Total & Male & 39 & 7 & 6 & 20 \\
\hline Total & All & 65 & 22 & 10 & 46 \\
\hline
\end{tabular}

Resistant means RHS-15 negative at both DME (T1) and CSE (T2), Delayed Distress means RHS-15 negative at DME and positive at CSE, Resilient means RHS-15 positive at DME and negative at CSE, Chronic Distress means RHS-15 positive at both DME and CSE. 
Distress on the RHS-15 generally paralleled that of the diagnostic proxies. Pearson's bivariate correlation between T1 RHS-15 total score and PTSD, Anxiety, and Depression scores were $0.90,0.87$, and 0.87 , respectively and between T2 RHS-15 total score and PTSD, Anxiety, and Depression were $0.89,0.91$, and 0.82 , respectively. Table 3 shows the number and group percentage of the 3 diagnostic proxies at both times.

Table 3. Diagnostic proxy number (\%) by country of origin at DME (T1) and CSE (T2).

\begin{tabular}{ccccccc}
\hline & \multicolumn{2}{c}{$\begin{array}{c}\text { Bhutan } \\
N=\mathbf{4 9}\end{array}$} & \multicolumn{2}{c}{ Iraq } & \multicolumn{2}{c}{$\begin{array}{c}\text { Burma } \\
\boldsymbol{N}=\mathbf{5 3}\end{array}$} \\
\cline { 2 - 7 } & DME & CSE & DME & CSE & DME & CSE \\
\hline PTSD & $10(20.4)$ & $21(42.9)$ & $26(49.1)$ & $32(60.4)$ & $6(14.6)$ & $5(12.2)$ \\
Anxiety & $9(18.4)$ & $17(34.7)$ & $20(37.8)$ & $24(45.3)$ & $4(9.8)$ & $0(0)$ \\
Depression & $9(18.4)$ & $21(42.9)$ & $20(37.8)$ & $24(45.3)$ & $4(9.8)$ & $0(0)$ \\
\hline
\end{tabular}

3.3. Impact of Trauma Severity, Resource Loss, Post-Migration Stress, and Self-Efficacy on Trajectory

Table 4 shows main effect differences by COU on all predictor variables. Burmese and Iraqis experienced significantly more war-related trauma ("trauma") than the Bhutanese, who experienced significantly more resource loss ("loss") than their counterparts. Bhutanese and Iraqis experienced similar levels of post-migration stress ("PMstress") and significantly more than the Burmese. Bhutanese rated themselves with higher levels of self-efficacy ("SE") compared with both Iraqis and Burmese, and Iraqis had higher levels than Burmese. A striking finding was that, in spite of less trauma and relatively high SE, the Bhutanese who showed moderate levels of distress at $\mathrm{T} 1$ and had the most delayed distress also had the most loss and significant PMstress.

Table 4. War Trauma, Loss, Post-migration stress, and self-efficacy by COU, M (SD).

\begin{tabular}{|c|c|c|c|c|c|}
\hline & Bhutan (1) & Iraq (2) & Burma (3) & Total Sample & Statistics \\
\hline $\begin{array}{l}\text { War-trauma } \\
\qquad N=133\end{array}$ & $16.4(3.7)$ & $20.5(7.6)$ & $21.2(5.9)$ & $19.4(6.4)$ & $\begin{array}{c}\mathrm{F}=8.01 ; p=0.001 \\
3>1 ; 2>1\end{array}$ \\
\hline $\begin{array}{c}\text { Resource } \\
\text { Loss } \\
N=139\end{array}$ & $50.9(21.5)$ & $35.0(24.0)$ & $19.6(17.8)$ & $36.4(24.7)$ & $\begin{array}{c}\mathrm{F}=22.67 ; p<0.001 \\
1>2 ; 1>3 ; 2>3\end{array}$ \\
\hline $\begin{array}{l}\text { PMStress } \\
N=127\end{array}$ & 33.5 (13.6) & 34.2 (18.7) & $25.6(15.1)$ & 31.8 (16.5) & $\begin{array}{c}\mathrm{F}=3.11 ; p=0.048 \\
1>3 ; 2>3\end{array}$ \\
\hline $\begin{array}{c}\text { Self- } \\
\text { Efficacy } \\
N=137\end{array}$ & $31.6(6.3)$ & $28.8(7.0)$ & $25.4(6.0)$ & $28.9(6.9)$ & $\begin{array}{l}\mathrm{F}=9.40 ; p<0.001 \\
1>2 ; 1>3 ; 2>3\end{array}$ \\
\hline
\end{tabular}

War trauma score is a sum of occurrences on the CTI-12; higher = more war trauma, Resource loss score is a sum of item severity score; higher = more loss, PM Stress score is the sum of item severity scores; higher = more PM stress, Self-efficacy score is the sum of item scores; higher = more self-efficacy.

Table 5 depicts the effects of predictor variables on trajectory assessed by ANOVA. War trauma is a stronger predictor of chronic distress and resilience compared to delayed distress. Loss is a highly significant predictor of both chronic and delayed distress. PMstress better predicts that chronic distress will be the most likely trajectory than either delayed distress or resistance, and delayed distress as more likely than resistance. Counterintuitively, higher SE best predicts a delayed distress trajectory over either a resilient or chronic distress trajectory. These data highlight the significant associations between fewer losses with resistance and resilience, and less PMstress with resistance. 
Table 5. ANOVA of predictor variables on trajectory.

\begin{tabular}{ccccccc}
\hline & Resistant (1) & Resilient (2) & $\begin{array}{c}\text { Delayed } \\
\text { Distress (3) }\end{array}$ & $\begin{array}{c}\text { Chronic } \\
\text { Distress (4) }\end{array}$ & Total & Statistics * \\
\hline War-trauma & $18.5(5.6)$ & $22.7(4.8)$ & $15.8(3.4)$ & $21.6(7.6)$ & $19.4(6.4)$ & $\mathrm{F}=5.8 ; p=0.001$ \\
$N=\mathbf{1 3 3}$ & $\mathrm{R}=12-40$ & $\mathrm{R}=15-33$ & $\mathrm{R}=12-27$ & $\mathrm{R}=12-44$ & $\mathrm{R}=12-44$ & $2>1 ; 2>3 ; 4>3$ \\
\hline $\begin{array}{c}\text { Resource } \\
\text { Loss }\end{array}$ & $24.8(20.5)$ & $23.6(16.9)$ & $38.7(20.3)$ & $54.0(23.1)$ & $36.4(24.7)$ & $\mathrm{F}=17.9 ; p<0.001$ \\
$N=\mathbf{1 3 9}$ & $\mathrm{R}=0-75$ & $\mathrm{R}=7-65$ & $\mathrm{R}=2-71$ & $\mathrm{R}=13-95$ & $\mathrm{R}=0-95$ & $4>1,2,3 ; 3>1$ \\
\hline $\begin{array}{c}\text { PMStress } \\
N=\mathbf{1 2 7}\end{array}$ & $22.4(13.5)$ & $\mathrm{R}=0-59.5(17.5)$ & $31.7(14.1)$ & $43.4(13.5)$ & $31.8(16.5)$ & $\mathrm{F}=18.4 ; p<0.001$ \\
\hline Self-Efficacy & $29.5(6.9)$ & $\mathrm{R}=16-67$ & $\mathrm{R}=4-63$ & $\mathrm{R}=16-68$ & $\mathrm{R}=0-68$ & $4>1,3 ; 3>1$ \\
$N=\mathbf{1 3 7}$ & $\mathrm{R}=15-40$ & $\mathrm{R}=11-36$ & $\mathrm{R}=22-40$ & $\mathrm{R}=8-38$ & $\mathrm{R}=8-40$ & $\mathrm{~F}=4.2 ; p=0.007$ \\
\hline
\end{tabular}

Values are Mean (SD) for each predictor variable, $\mathrm{R}=$ range of score for predictor variable by trajectory type, ${ }^{*}$ Multiple comparisons with Bonferroni correction, group difference at $p<0.05$.

Table 6 shows three regression models of predictor variables on trajectory. Each model was significant and a good fit for the data. Predictor variables trauma, loss, PMstress, and SE were entered into the first regression model using the forced method to ensure replicability. The first regression model produced $\mathrm{R}^{2}=0.42, \mathrm{~F}(4,114)=20.92, p<0001$, where loss $(\beta=0.44, p<0.001)$, PMstress $(\beta=0.27, p=0.004)$, and SE $(\beta=-0.15, p<0.05)$ all contributed differentially to the model. Loss has the greatest effect on trajectory.

Table 6. Three regression models of predictor variables on trajectory, $\beta$, ( $p$ value).

\begin{tabular}{|c|c|c|c|c|c|c|c|c|}
\hline Model & Loss & PMstress & Trauma & SE & COU & Gender & RHS DME & Stats \\
\hline 1 & $0.44(<0.01)$ & $0.27(<0.01)$ & NS & $-0.15(0.05)$ & - & - & - & $\begin{array}{c}\mathrm{R}^{2}=0.42 \\
\mathrm{~F}=20.9\end{array}$ \\
\hline 2 & $0.35(<0.01)$ & $0.28(<0.01)$ & NS & $-0.17(0.03)$ & NS & $0.15(0.04)$ & - & $\begin{array}{c}R^{2}=0.46 \\
F=15.7\end{array}$ \\
\hline 3 & NS & $0.19(0.03)$ & NS & NS & NS & NS & $0.64(<0.01)$ & $\begin{array}{c}R^{2}=0.53 \\
F=17.6\end{array}$ \\
\hline
\end{tabular}

When the variables gender and COU were added to the regression model, a slight increase in variance was observed $\left(R^{2}=0.46, F(6,112)=15.71, p<0001\right)$. The associations between gender-Trajectory and COU-Trajectory were both weak relationships, and the added variance was small though significant for gender $(\beta=0.15, p=0.037)$ but not for $\operatorname{COU}(\beta=0.15, p=0.112)$. Loss $(\beta=0.35, p=0.001)$, PMstress $(\beta=0.28, p=0.002)$, and SE $(\beta=-0.17, p=0.025)$ remained significant after the addition of gender and COU to the model.

In the third regression model, T1 RHS Score was added to the model and increased observed variance $\left(\mathrm{R}^{2}=0.53, \mathrm{~F}(7,111)=17.61, p<001\right)$. T1 RHS score was significantly associated with Trajectory $(r=0.64, p<0.001)$. PMstress accounted for markedly less yet still significant variance $(\beta=0.19, p=0.03)$, and loss $(\beta=0.12, p=0.27)$ and SE $(\beta=-0.06$, $p=0.45)$ were no longer significant.

Since loss was a strong predictor of delayed and chronic distress, probability analyses were conducted to show interactive effects of loss by trajectory type. Figure 2 shows that, with a low loss score (e.g., 10), the likelihood of resistance, resilience, delayed distress, and chronic distress at an RHS cut score of 12 at $\mathrm{T} 1$ is $0.28,0.35,0.07$, and 0.30 , respectively, while with a high loss score (i.e., 50 ), probabilities are $0.11,0.10,0.11$, and 0.68 , respectively. 

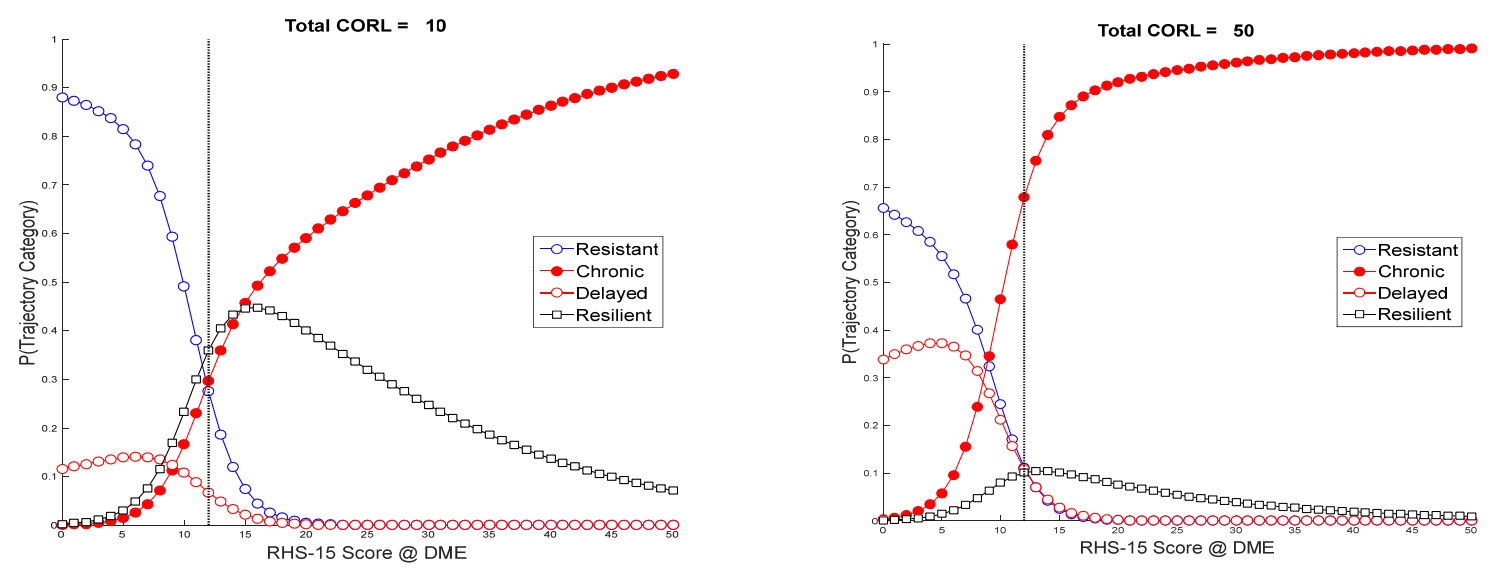

Figure 2. Effect of loss score on trajectory probability.

\section{Discussion}

The first hypothesis, that distress trajectory type during early resettlement varied by COU, was confirmed. Trajectory type did not vary by gender. The Burmese showed the highest prevalence of resistance $(68 \%)$ and resilience $(15 \%)$, in addition to relatively low delayed $(7 \%)$ and chronic $(10 \%)$ distress. Seventy-six percent of Burmese were not distressed on arrival and of the relatively low 10 persons (24\%) that were distressed on arrival only 3 ( $7 \%$ of total Burmese sample and $30 \%$ of the initially distressed) remained distressed at the second assessment. On the other hand, six persons $(15 \%$ of the Burmese sample and $60 \%$ of initially distressed) became non-distressed by the second visit. Nepali Bhutanese showed different patterns: there was a 33\% prevalence of distress on arrival, none became non-distressed by the CME, and 15 of 31 persons ( $31 \%$ of the Bhutanese sample and $45 \%$ of initially non-distressed) became distressed, resulting in $64 \%$ being distressed at the CSE. The Bhutanese thus had the highest prevalence of delayed distress among the three groups. Iraqi's had the greatest initial rates of distress $(57 \%)$ which remained stable on a population basis from DME to CSE: 7.5\% of those distressed became non-distressed, and $7.5 \%$ of initially non-distressed persons became distressed. Iraqi's thus showed the highest prevalence of chronic distress.

A few critical themes emerge from these results. First, the large minority of newlyresettled refugees in all three COU groups are resistant to the severe stress experienced during war, oppression, and migration. The majority $(60 \%)$ were not significantly distressed at the initial examination, and the most likely trajectory was resistant $(45 \%)$. The second theme was that distress from T1 to T2 was stable. Those who were initially distressed were not likely to get better in the initial resettlement period: across all groups only $8 \%$ followed the resilient trajectory. The second and third most likely trajectories were chronic (32\%) and delayed (15\%) distress respectively. Stability over time, both resistance and chronic distress, was thus most likely and was primarily a function of distress score at the initial domestic medical examination. Change, both resilience and delayed distress was less common and primarily a function of country of origin. In all, $22(15 \%)$ refugees experienced delayed distress, 15 of whom were Bhutanese, while 10 (7\%) experienced resilience, six of whom were Burmese. It is not clear from our data if treatment engagement had any impact on trajectory type since only $19 \%$ of the sample at T1 engaged in treatment and outcome data were not available.

The second hypothesis, that trauma severity, post-migration stress, resource loss, and self-efficacy would have some predictive capacity for, or explain some variance in distress trajectory experienced was also supported in part. ANOVA with post-hoc pair analyses showed that some of these four predictor variables differed between country groups, which in turn had some predictive capacity for distress trajectory. Burmese and Iraqi's suffered more war-trauma (by the CTI-12) than Bhutanese. Bhutanese reported more 
loss than Iraqi's, and both of these groups reported more loss and post-migration stress and endorsed higher self-efficacy than Burmese. Those experiencing the resilient trajectory had significantly more war-trauma than those on the resistant or delayed distress trajectory, and those with chronic distress had more trauma than those with delayed distress. Put another way, those with initial distress tended to have experienced more war trauma than those who were not initially distressed. Refugees with chronic distress reported more resource loss than refugees on the other three trajectories, and those with delayed distress had more loss than those on the resistant trajectory. The same basic pattern was true for post-migration stress, except that those on the resilient trajectory tended to have lower post-migration stress than those with chronic distress, though this was not statistically significant. Delayed distress was associated with higher initial self-efficacy compared to those resilient or with chronic distress. One interpretation is that perceived self-efficacy at the initial evaluation protects against reporting of initial distress, but other factors such as post-migration stress are more powerful in creating distress over time. This may help explain what has been termed the "honeymoon" period [47], where refugees report a sense of wellbeing during early resettlement due to being in a new country with perceived new opportunities, but slowly lose the sense of wellbeing as exposure to a myriad of post-migration stressors and hardships increase. While trauma severity, post-migration stress, resource loss, and self-efficacy had some predictive capacity on trajectory, initial distress was, however, overwhelmingly the best predictor of trajectory.

While this is the first study we know of that examines factors associated with specific distress trajectory types in adult refugees of war, these data are supported by other work evaluating effects of both pre- and post-migration factors on distress. Earlier studies showed that post-migration stress in addition to war-trauma contributes to poor mental health in refugees $[60,65,66]$. Research in the past decade has verified that demographic and post-migration variables influence refugee distress [3,6,9,10,67-69]. A number of studies evaluating the relative contribution of types of stressors have found that postmigration stress often provides a risk for distress similar to or greater than war-related trauma $[3,7,9,61,70-72]$. Pre- and post-migration stress may differentially predict specific kinds of symptoms and distress in both children and adults [73,74]. Lost resources and ongoing stressors have been consistently found to predict the risk for developing and maintaining a stress-related illness following trauma in war survivors, as well as in survivors of natural disasters, terrorist attacks, intimate partner violence, and sexual assault [40,59,75-81]. Recent work has deepened knowledge about variables associated with refugee distress, such as gender, age, religion practiced, receipt of medical services, instability of housing [82], negative life events and employment status [37]. With recognition of the contributions of loss and ongoing stress to the health of war survivors, investigators are pursuing a broader social ecological model of trauma and recovery [83]. To determine how this knowledge may be utilized to encourage trauma recovery, Betancourt and colleagues conducted focus groups with Somali refugee adolescents, mothers, and fathers to identify five forms of resources-religious faith, healthy family communication, support networks, peer support, and community talk - that may have been compromised during war and flight- that are potentially protective if restored and can help to offset acculturative and resettlement stressors [84].

The growing evidence for effective interventions for refugees [85-94], coupled with the significant prevalence of distress and attendant risks of ongoing morbidity and mortality, argues for universal screening for newly resettled refugees. The current study data suggest that screening should occur at least twice in the course of resettlement to detect those with initial distress and the significant number of those with delayed distress. Screening should, of course, be coupled with identifying other social determinants of health and a comprehensive assessment to determine the need for intervention for secondary prevention (i.e., reducing delayed distress) and treatment (reducing chronic distress). Other investigators have also found a significant prevalence of chronic distress to support this conclusion $[37,68]$. What is not clear from this or other research is: (1) the best timing 
of the second screening, (2) who may not need a second screening, and (3) the public health benefit of screening on health outcomes. Until more data are available to clarify these questions, screening should be conducted in a reliable manner by personnel who are trained to administer and properly interpret and act on screening information. Similar to screening for any other health condition, screening for emotional distress and psychiatric disorder is distinct from diagnostic assessment or treatment planning, which needs to be conducted by persons skilled in these tasks.

Study limitations include a sample with only three groups from three countries, inclusion of a limited number of predictor variables, high variability of scores on predictor variables, and inability to account for concurrent treatment. Thus, conclusions about the generalizability of these data to other COU groups is not possible, all factors accounting for distress are not identified, and predictions about distress trajectory for individuals is less reliable than for groups and is not informed by concurrent treatment. Complex multivariate modeling utilizing more predictor variables with a larger sample from different countries and contexts may allow for more definitive conclusions about the effects of contextual variables on distress/non-distress trajectories in newly resettled refugees. Constructs of distress and trajectory are narrowly defined, where broader construct definitions may produce different results. Defining and assessing each construct using scales developed from Western education can also present challenges of validity, particularly for less literate participants. In spite of these limitations, the four hypothesized predictor variables explained $42 \%$ of the trajectory type variance, and with the addition of country of origin, gender and initial distress, the model accounted for $53 \%$ of the variance.

\section{Conclusions}

The current study adds to the body of knowledge by estimating the prevalence of specific distress trajectory types and identifying important variables that account for $53 \%$ of the variance of trajectory type in adult refugees of war after resettlement in the U.S. It also further reifies literature that favors early intervention by screening refugees for emotional distress at least twice during resettlement and supports our contention that assessing loss and post-migration stress will augment extant clinical information about who is likely to stay distressed, become distressed, or be resilient.

Author Contributions: Conceptualization by M.H., E.C.T., S.V.-K., B.F., J.Y.; Methodology by M.H. and E.C.T.; Software by E.C.T.; Validation and Formal Analysis by M.H. and E.C.T.; Data Curation by S.V.-K., T.W., A.H.; Writing-Original Draft Preparation by M.H.; Writing-Review \& Editing by E.C.T., S.V.-K., B.F., J.Y., TW., A.H.; Project Administration by B.F., M.H., S.V.-K.; Funding Acquisition by B.F., J.Y. All authors have read and agreed to the published version of the manuscript.

Funding: The Pathways to Wellness project was generously supported by the Robert Wood Johnson Foundation, The Bill and Melinda Gates Foundation, M.J. Murdock Trust, United Way of King County, The Medina Foundation, The Seattle Foundation, and the Boeing Employees Community Fund.

Institutional Review Board Statement: The study was conducted according to the guidelines of the Declaration of Helsinki, and approved by the Institutional Review Board of the Pacific Institute for Research and Evaluation (\#0470, IRB00004721, 11/18/2009) and the ethics committee at Public Health Seattle and King County (PHSKC) (Statement of confidentiality and compliance, 8/6/2010).

Informed Consent Statement: Written informed consent was obtained from all subjects involved in the study unless they refused, in which case documented verbal consent was obtained.

Data Availability Statement: The data presented in this study are available on request from the corresponding author. The data are not publicly available due to initial informed consent agreements with this vulnerable population.

Acknowledgments: Funding Agencies: Project Partners: Pathways to Wellness: Integrating Community Health and Well-being is a project of Lutheran Community Services Northwest, Asian Counseling and Referral Services, Public Health Seattle \& King County, and The Pacific Institute for Research and Evaluation. Collaborative Assistance: We appreciate the multiple translators and community refugee focus group participants. We also appreciate our collaborators across the world who are utilizing the 
RHS-15 for clinical and research purposes. Thank you to Kala Carrick for statistical assistance and to Andrea Gory Munoz and Ruth Alpert for formatting. Distribution Assistance: We thank the Refugee Health Technical Assistance Center, the Center for Victims of Torture, the Society for the Study of Psychiatry and Culture, and the North American Refugee Health Conference for featuring this work in virtual or on-site conferences.

Conflicts of Interest: Authors do not have conflict of interest to report. None declared.

\section{References}

1. United Nations High Commissioner for Refugees (UNHCR). Available online: https://www.unhcr.org/en-us / figures-at-aglance.html (accessed on 9 November 2020).

2. Fazel, M.; Wheeler, J.; Danesh, J. Prevalence of serious mental disorder in 7000 refugees resettled in western countries: A systematic review. Lancet 2005, 365, 1309-1314. [CrossRef]

3. Fenta, H.; Hyman, I.; Noh, S. Determinants of depression among ethiopian immigrants and refugees in Toronto. J. Nerv. Ment. Dis. 2004, 192, 363-372. [CrossRef] [PubMed]

4. Hollifield, M.; Warner, T.D.; Krakow, B.; Jenkins, J.; Westermeyer, J. The range of symptoms in refugees of war: The New Mexico refugee symptom checklist-121. J. Nerv. Ment. Dis. 2009, 197, 117-125. [CrossRef] [PubMed]

5. Jaranson, J.M.; Butcher, J.; Halcon, L.; Johnson, D.R.; Robertson, C.; Savik, K.; Spring, M.; Westermeyer, J. Somali and oromo refugees: Correlates of torture and trauma history. Am. J. Public Health 2004, 94, 591-598. [CrossRef] [PubMed]

6. Laban, C.J.; Gernaat, H.B.; Komproe, I.H.; van der Tweel, I.; De Jong, J.T. Postmigration living problems and common psychiatric disorders in Iraqi Asylum seekers in the Netherlands. J. Nerv. Ment. Dis. 2004, 193, 825-832. [CrossRef]

7. Marshall, G.N.; Schell, T.L.; Elliot, M.N.; Berthold, S.M.; Chun, C. Mental health of cambodian refugees 2 decades after resettlement in the United States. JAMA 2005, 294, 571-579. [CrossRef]

8. Weine, S.M.; Kulenovic, A.D.; Pavkovic, I.; Gibbons, R. Testimony psychotherapy in bosnian refugees: A pilot study. Am. J. Psychiatry 1998, 155, 1720-1726. [CrossRef]

9. Momartin, S.; Steel, Z.; Coello, M.; Aroche, J.; Silove, D.M.; Brooks, R. A comparison of the mental health of refugees with temporary versus permanent protection visas. Med. J. Aust. 2006, 185, 357-361. [CrossRef]

10. Porter, M.; Haslam, N. Predisplacement and postdisplacement factors associated with mental health of refugees and internally displaced persons: A meta-analysis. JAMA 2005, 294, 602-612. [CrossRef]

11. de Jong, J.T.; Komproe, I.H.; Van Ommeren, M.; El Masri, M.; Araya, M.; Khaled, N.; van De Put, W.; Somasundaram, D. Lifetime events and posttraumatic stress disorder in 4 postconflict settings. JAMA 2001, 286, 555-562. [CrossRef]

12. Mollica, R.; McInnes, K.; Pham, T.; Smith Fawzi, M.C.; Murphy, E.; Lin, L. The dose-effect relationships between torture and psychiatric symptoms in vietnamese ex-political detainees and a comparison group. J. Nerv. Ment. Dis. 1998, 186, 543-553. [CrossRef] [PubMed]

13. Hollifield, M.; Warner, T.D.; Jenkins, J.; Sinclair-Lian, N.; Krawkow, B.; Eckert, V.; Karadaghi, P.; Westermeyer, J. Assessing war trauma in refugees: Properties of the comprehensive trauma inventory-104 (CTI-104). J. Trauma. Stress 2006, 19, 527-540. [CrossRef] [PubMed]

14. Boscarino, J.A. Posttraumatic stress disorder and mortality among U.S. army veterans 30 years after military service. Ann. Epidemiol. 2006, 16, 248-256. [CrossRef] [PubMed]

15. Boscarino, J.A.; Chang, J. Electrocardiogram abnormalities among men with stress-related psychiatric disorders: Implications for coronary heart disease and clinical research. Ann. Behav. Med. 1999, 21, 227-234. [CrossRef] [PubMed]

16. Boscarino, J.A. Diseases among men 20 years after exposure to severe stress: Implications for clinical research and medical care. Psychosom. Med. 1997, 59, 605-614. [CrossRef] [PubMed]

17. Cwikel, J.; Abdelgani, A.; Goldsmith, J.R.; Quastel, M.; Yevelson, I.I. Two-year follow up study of stress-related disorders among immigrants to israel from the chernobyl area. Environ. Health Perspect. 1997, 105, 1545-1550. [CrossRef]

18. Dobie, D.J.; Kivlahan, D.R.; Maynard, C.; Bush, K.R.; Davis, T.M.; Bradley, K.A. Posttraumatic stress disorder in female veterans: Association with self-reported health problems and functional impairment. Arch. Intern. Med. 2004, 164, 394-400. [CrossRef]

19. Falger, P.R.; Op den Velde, W.; Hovens, J.E.; Schouten, E.G.; De Groen, J.H.; Van Duijn, H. Current posttraumatic stress disorder and cardiovascular disease risk factors in dutch resistance veterans from World War II. Psycother. Psychosom. 1992, 57, 164-171. [CrossRef]

20. Gander, M.L.; von Känel, R. Myocardial infarction and post-traumatic stress disorder: Frequency, outcome, and atherosclerotic mechanisms. Eur. J. Cardiovasc. Prev. Rehabil. 2006, 13, 165-172. [CrossRef]

21. Sawchuk, C.N.; Roy-Byrne, P.; Goldberg, J.; Manson, S.; Noonan, C.; Beals, J.; Buchwald, D. The relationship between post-traumatic stress disorder, depression and cardiovascular disease in an american indian tribe. Psychol. Med. 2005, 35, 1785-1794. [CrossRef]

22. Schnurr, P.P.; Spiro, A.; Paris, A.H. Physician-diagnosed medical disorders in relation to PTSD symptoms in older male military veterans. Health Psychol. 2000, 19, 91-97. [CrossRef] [PubMed]

23. Shemesh, E.; Yehuda, R.; Milo, O.; Dinur, I.; Rudnick, A.; Vered, Z.; Cotter, G. Posttraumatic stress, nonadherence, and adverse outcome in survivors of a myocardial infarction. Psychosom. Med. 2004, 66, 521-526. [CrossRef] [PubMed] 
24. Boscarino, J.A. Posttraumatic stress disorder and physical illness: Results from clinical and epidemiologic studies. Ann. N. Y. Acad. Sci. 2004, 1032, 141-153. [CrossRef] [PubMed]

25. Kimerling, R. An investigation of sex differences in nonpsychiatric morbidity associated with posttraumatic stress disorder. J. Am. Med. Womens Assoc. 2004, 59, 43-47.

26. Weisberg, R.B.; Bruce, S.E.; Machan, J.T.; Kessler, R.C.; Culpepper, L.; Keller, M.B. Nonpsychiatric illness among primary care patients with trauma histories and posttraumatic stress disorder. Psychiatr. Serv. 2002, 53, 848-854. [CrossRef]

27. Rohleder, N.; Karl, A. Role of endocrine and inflammatory alterations in comorbid somatic diseases of post-traumatic stress disorder. Minerva Endocrinol. 2006, 31, 273-288.

28. Asgary, R.; Segar, N. Barriers to health care access among refugee asylum seekers. J. Health Care Poor Underserved 2011, 22, 506-522. [CrossRef]

29. Wong, E.C.; Marshall, G.N.; Schell, T.L.; Elliott, M.N.; Babey, S.H.; Hambarsoomians, K. The unusually poor physical health status of cambodian refugees two decades after resettlement. J. Immigr. Minor Health 2011, 13, 876-882. [CrossRef]

30. Centers for Disease Control and Prevention. Guidelines for Mental Health Screening during the Domestic Medical Examination for Newly Arrived Refugees. Available online: http://www.cdc.gov/immigrantrefugeehealth/guidelines/domestic/mentalhealth-screening-guidelines.html (accessed on 9 November 2020).

31. Ovitt, N.; Larrison, C.R.; Nackerud, L. Refugees' response to mental health screening. Int. Soc. Work 2003, 49, 235-250. [CrossRef]

32. Lie, B. A 3-year follow-up study of psychosocial functioning and general symptoms in settled refugees. Acta. Psychiatr. Scand. 2002, 106, 415-425. [CrossRef]

33. Ryan, D.A.; Benson, C.A.; Dooley, B.A. Psychological distress and the asylum process: A longitudinal study of forced migrants in Ireland. J. Nerv. Ment. Dis. 2008, 196, 37-45. [CrossRef] [PubMed]

34. Steel, Z.; Momartin, S.; Silove, D.; Coello, M.; Aroche, J.; Tay, K.W. Two year psychosocial and mental health outcomes for refugees subjected to restrictive or supportive immigration policies. Soc. Sci. Med. 2011, 72, 1149-1156. [CrossRef] [PubMed]

35. Roth, G.; Ekbald, S.; Agren, H. A longitudinal study of PTSD in a sample of adult mass-evacuated kosovars, some of whom returned to their home country. Eur. Psychiatry 2006, 21, 152-159. [CrossRef] [PubMed]

36. Mollica, R.F.; Sarajlic, N.; Chernoff, M.; Lavelle, J.; Vukovic, I.S.; Massagli, M.P. Longitudinal study of psychiatric symptoms, disability, mortality, and emigration among bosnian refugees. JAMA 2001, 286, 546-554. [CrossRef] [PubMed]

37. Kaltenbach, E.; Schauer, M.; Hermenau, K.; Elbert, T.; Schalinski, I. Course of mental health in refugees-a one year panel survey. Front. Psychiatry 2018, 9, 352. [CrossRef]

38. Comtesse, H.; Powell, S.; Soldo, A.; Hagi, M.; Rosner, R. Long-term psychological distress of Bosnian war survivors: An 11-year follow-up of former displaced persons, returnees, and stayers. BMC Psychiatry 2019, 19, 1-10. [CrossRef]

39. Muller, L.R.F.; Gossmann, K.; Hartmann, F.; Buter, K.P.; Rosner, R.; Unterhitzenberger, J. 1-year follow-up of the mental health and stress factors in asylum-seeking children and adolescents resettled in Germany. BMC Pub. Health 2019, 19, 1-11. [CrossRef]

40. Hobfoll, S.E.; Palmieri, P.A.; Johnson, R.J.; Canetti-Nisim, D.; Hall, B.J.; Galea, S. Trajectories of resilience, resistance, and distress during ongoing terrorism: The case of jews and arabs in Israel. J. Consult. Clin. Psychol. 2009, 77, 138-148. [CrossRef]

41. Westermeyer, J.; Janca, A. Language, culture and psychopathology: Conceptual and methodological issues. Transcult. Psychiatry 1997, 34, 291-311. [CrossRef]

42. Brislin, R.W. Back-translation for cross-cultural research. J. Cross. Cult. Psychol. 1970, 1, 187-216. [CrossRef]

43. Hollifield, M.; Verbillis-Kolp, S.; Farmer, B.; Toolson, E.C.; Woldehaimanot, T.; Yamazaki, J.; Holland, A.; St Clair, J.; SooHoo, J. The refugee health screener-15 (RHS-15): Development and validation of an instrument for anxiety, depression, and PTSD in Refugees. Gen. Hosp. Psychiatry 2013, 35, 202-209. [CrossRef] [PubMed]

44. Hollifield, M.; Toolson, E.C.; Verbillis-Kolp, S.; Farmer, B.; Yamazaki, J.; Woldehaimanot, T.; Holland, A. Effective screening for emotional distress in refugees: The refugee health screener. J. Nerv. Ment. Dis. 2016, 204, 247-253. [CrossRef] [PubMed]

45. Kaltenbach, E.; Härdtner, E.; Hermenau, K.; Schauer, M.; Elbert, T. Efficient identification of mental health problems in refugees in Germany: The refugee health screener. Eur. J. Psychhotraumatol. 2017, 8, 1389205. [CrossRef] [PubMed]

46. Bjärtå, A.; Leiler, A.; Ekdahl, J.; Wasteson, E. Assessing severity of psychological distress among refugees with the refugee health screener, 13-item version. J. Nerv. Ment. Dis. 2018, 206, 834-839. [CrossRef] [PubMed]

47. Polcher, K.; Calloway, S. Addressing the need for mental health screening of newly resettled refugees: A pilot project. J. Prim. Care Community Health 2016, 7, 199-203. [CrossRef]

48. Hollifield, M.; Warner, T.D.; Lian, N.; Krakow, B.; Jenkins, J.H.; Kesler, J.; Stevenson, J.; Westermeyer, J. Measuring trauma and health status in refugees: A critical review. JAMA 2002, 288, 611-621. [CrossRef]

49. Derogatis, L.R.; Lipman, R.S.; Rickels, K.; Uhlenhuth, E.H.; Covi, L. The hopkins symptom checklist (HSCL): A measure of primary symptom dimensions. Mod. Probl. Pharm. 1974, 79-110. [CrossRef]

50. Mollica, R.F.; Wyshak, G.; de Marneffe, D.; Khuon, F.; Lavelle, J. Indochinese versions of the hopkins symptom checklist-25: A screening instrument for the psychiatric care of refugees. Am. J. Psychiatry 1987, 144, 497-500. [CrossRef]

51. Winokur, A.; Winokur, D.F.; Rickels, K.; Cox, D.S. Symptoms of emotional distress in a family planning service: Stability over a four-week period. Br. J. Psychiatry 1984, 144, 395-399. [CrossRef]

52. Butcher, J.N. Psychological evaluation. In Mental Health Services for Refugees; Westermyer, J., Williams, C., Nguyen, A., Eds.; Government Printing Office: Washington, DC, USA, 1991; pp. 111-122. 
53. Kinzie, J.D.; Manson, S.M. The use of self-rating scales in cross-cultural psychiatry. Hosp. Community Psychiatry 1987, 38, 190-196. [CrossRef]

54. Foa, E.B.; Riggs, D.S.; Dancu, C.V.; Rothbaum, B.O. Reliability and validity of a brief instrument for asessing post-traumatic stress disorder. J. Trauma. Stress 1993, 6, 459-473. [CrossRef]

55. Hollifield, M.; Eckert, V.; Warner, T.D.; Jenkins, J.; Krakow, B.; Ruiz, J.; Westermeyer, J. Development of an inventory for measuring war-related events in refugees. Compr. Psychiatry 2005, 46, 67-80. [CrossRef] [PubMed]

56. Hobfoll, S.E.; Lilly, R.S. Resource conservation as a strategy for community psychology. J. Community Psychol. 1993, 21, 128-148. [CrossRef]

57. Hobfoll, S.E.; Tracy, M.; Galea, S. The impact of resource loss and traumatic growth on grobable PTSD and depression following terrorist attacks. J. Trauma Stress 2006, 19, 867-878. [CrossRef] [PubMed]

58. Hobfoll, S.E.; Canetti-Nisim, D.; Johnson, R.J. Exposure to terrorism, stress-related mental health symptoms, and defensive coping among Jews and Arabs in Israel. J. Consult. Clin. Psychol. 2006, 74, 207-218. [CrossRef] [PubMed]

59. Hollifield, M.; Gory, A.; Siedjak, J.; Nguyen, L.; Holmgreen, L.; Hobfoll, S. The benefit of conserving and gaining resources after trauma: A systematic review. J. Clin. Med. 2016, 5, 104. [CrossRef]

60. Silove, D.; Sinnerbrick, I.; Manicavasagar, V.; Steel, Z. Anxiety, depression and PTSD in asylum-seekers: Associations with pre-migration trauma and post-migration stressors. Br. J. Psychiatry 1997, 170, 351-357. [CrossRef]

61. Steel, Z.; Silove, D.; Bird, K.; McGorry, P.; Mohan, P. Pathways from war trauma to posttraumatic stress symptoms among tamil asylum seekers, refugees, and immigrants. J. Trauma Stress 1999, 12, 421-435. [CrossRef]

62. Silove, D.; Steel, Z.; McGorry, P.; Mohan, P. Trauma exposure, postmigration stressors, and symptoms of anxiety, depression and post-traumatic stress in tamil asylum-seekers: Comparison with refugees and immigrants. Acta. Psychiatr. Scand. 1998, 97, 175-181. [CrossRef]

63. Schwarzer, R.; Jerusalem, M. Generalized self-efficacy scale. In Measures in Health Psychology: A User's Portfolio. Causal and Control Beliefs; Weinman, J., Johnston, M., Eds.; GL Assessment Limited: Windsor, UK, 1995; pp. 35-37.

64. Kass, R.E.; Raftery, A.E. Bayes factors. J. Am. Stat. Assoc. 1995, 90, 773-795. [CrossRef]

65. Beiser, M. Strangers at the Gate. The Boat People's First Ten Years in Canada; University of Toronto Press: Toronto, ON, Canada, 1999.

66. Westermeyer, J.; Vang, T.F.; Neider, J. Migration and mental health among hmong refugees. Association of Pre-and postmigration factors with self-rating scales. J. Nerv. Mental Dis. 1983, 171, 92-96. [CrossRef] [PubMed]

67. Carswell, K.; Blackburn, P.; Barker, C. The relationship between trauma, post-migration problems and the psychological well-being of refugees and asylum seekers. Int. J. Soc. Psychiatry 2011, 57, 107-119. [CrossRef] [PubMed]

68. Carlsson, J.M.; Mortensen, E.L.; Kastrup, M. Predictors of mental health and quality of life in male tortured refugees. Nord. J. Psychiatry 2006, 60, 51-57. [CrossRef] [PubMed]

69. Schweitzer, R.; Melville, F.; Steel, Z.; Lacherez, P. Trauma, post-migration living difficulties, and social support as predictors of psychological adjustment in resettled sudanese refugees. Aust. N. Z. J. Psychiatry 2006, 40, 179-187. [CrossRef] [PubMed]

70. Lindencrona, F.; Ekblad, S.; Hauff, E. Mental health of recently resettled refugees from the middle east in Sweden: The impact of pre-resettlement trauma, resettlement stress and capacity to handle stress. Soc. Psychiatry Psychiatr. Epidemiol. 2008, 43, 121-131. [CrossRef]

71. Schweitzer, R.D.; Brough, M.; Vromans, L.; Asic-Kobe, M. Mental health of newly arrived burmese refugees in Australia: Contributions of pre-migration and post-migration experience. Aust. N. Z. J. Psychiatry 2011, 45, 299-307. [CrossRef] [PubMed]

72. Hollifield, M.; Warner, T.D.; Krakow, B.; Westermeyer, J. Mental health effects of stress over the life span of refugees. J. Clin. Med. 2018, 7, 25. [CrossRef]

73. Birman, D.; Tran, N. Psychological distress and adjustment of vietnamese refugees in the United States: Association with preand postmigration factors. Am. J. Orthopsychiatry 2008, 78, 109-120. [CrossRef]

74. Heptinstall, E.; Sethna, V.; Taylor, E. PTSD and depression in refugee children: Associations with pre-migration trauma and post-migration stress. Eur. Child Adolesc. Psychiatry 2004, 13, 373-380. [CrossRef]

75. Hall, B.J.; Hobfoll, S.E.; Palmieri, P.A.; Canetti-Nisim, D.; Shapira, O.; Johnson, R.J.; Galea, S. The psychological impact of impending forced settler disengagement in Gaza: Trauma and posttraumatic growth. J. Trauma Stress 2008, 21, 22-29. [CrossRef]

76. Lindhorst, T.; Oxford, M.; Gillmore, M.R. Longitudinal effects of domestic violence on employment and welfare outcomes. J. Interpers. Violence 2007, 22, 812-828. [CrossRef] [PubMed]

77. Monnier, J.; Resnick, H.S.; Kilpatrick, D.G.; Brenda, S. The relationship between distress and resource loss following rape. Violence Vict. 2002, 17, 85-91. [CrossRef] [PubMed]

78. Norris, F.H.; Friedman, M.J.; Watson, P.J. 60,000 disaster victims speak: Part II. Summary and implications of the disaster mental health research. Psychiatry J. 2002, 65, 240-260. [CrossRef] [PubMed]

79. Palmieri, P.A.; Canetti-Nisim, D.; Galea, S.; Johnson, R.J.; Hobfoll, S.E. The psychological impact of the israel-hezbollah war on jews and arabs in Israel: The impact of risk and resilience factors. Soc. Sci. Med. 2008, 67, 1208-1216. [CrossRef] [PubMed]

80. Silver, R.C.; Holman, E.A.; McIntosh, D.N.; Poulin, M.; Gil-Rivas, V. Nationwide longitudinal study of psychological responses to September 11. JAMA 2002, 288, 1235-1244. [CrossRef]

81. Smith, B.W.; Freedy, J.R. Psychosocial rresource loss as a mediator of the effects of flood exposure on psychological distress and physical symptoms. J. Trauma Stress 2000, 13, 349-357. [CrossRef] 
82. Song, S.J.; Kaplan, C.; Tol, W.A.; Subica, A.; de Jong, J. Psychological distress in torture survivors: Pre- and post-migration risk factors in a US sample. Soc. Psychiatry Psychiatr. Epidemiol. 2015, 50, 549-560. [CrossRef]

83. Miller, K.E.; Rasmussen, A. The mental health of civilians displaced by armed conflict: An ecological model of refugee distress. Epidemiol. Psychiatr. Sci. 2017, 26, 129-138. [CrossRef]

84. Betancourt, T.S.; Frounfelker, R.; Mishra, T.; Hussein, A.; Falzarano, R. Addressing health disparities in the mental health of refugee children and adolescents through community-based participatory research: A study in 2 communities. Am. J. Public Health 2015, 105, S475-S482. [CrossRef]

85. van Wyk, S.; Schweitzer, R.; Brough, M.; Vromans, L.; Murry, K. A Longitudinal study of mental health in refugees from burma: The impact of therapeutic interventions. Aust. N. Z. J. Psychiatry 2012, 46, 995-1003. [CrossRef]

86. Nickerson, A.; Bryant, R.A.; Silove, D.; Steel, Z. A critical review of psychological treatments of posttraumatic stress disorder in refugees. Clin. Psychol. Rev. 2011, 31,399-417. [CrossRef] [PubMed]

87. Boynton, L.; Bentley, J.; Strachan, E.; Barbato, A.; Raskind, M. Preliminary findings concerning the use of prazosin for the treatment of posttraumatic nightmares in a refugee population. J. Psychiatr. Pract. 2009, 15, 454-459. [CrossRef] [PubMed]

88. Hinton, D.E.; Hofmann, S.G.; Pollack, M.H.; Otto, M.W. Mechanisms of efficacy of CBT for cambodian refugees with PTSD: Improvement in emotion regulation and orthostatic blood pressure response. CNS Neurosci. Ther. 2009, 15, 255-263. [CrossRef] [PubMed]

89. Hinton, D.E.; Chhean, D.; Pich, V.; Safren, S.A.; Hofmann, S.G.; Pollack, M.H. A randomized controlled trial of cognitive-behavior therapy for cambodian refugees with treatment-resistant PTSD and panic attacks: A cross-over design. J. Trauma Stress 2005, 8, 617-629. [CrossRef]

90. Otto, M.W.; Hinton, D.E. Modifying exposure-based CBT for cambodian refugees with posttraumatic stress disorder. Cogn. Behav. Pract. 2006, 13, 261-270. [CrossRef]

91. Paunovic, N.; Ost, L.G. Cognitive-behavior therapy vs exposure therapy in the treatment of PTSD in refugees. Behav. Res. Ther. 2001, 39, 1183-1197. [CrossRef]

92. Renner, W. The effectiveness of psychotherapy with refugees and asylum seekers: Preliminary results from an austrian study. $J$. Immigr. Minor. Health 2009, 11, 41-45. [CrossRef]

93. Smajkic, A.; Weine, S.; Djuric-Bijedic, Z.; Boskailo, E.; Lewis, J.; Pavkovic, I. Sertraline, paroxetine, and venlafaxine in refugee posttraumatic stress disorder with depression symptoms. J. Trauma Stress 2001, 14, 445-452. [CrossRef]

94. Bager, L.; Hansen, K.S.; Andersen, C.J.; Wang, S.J. Does multidisciplinary rehabilitation of tortured refugees represent 'value-formoney'? A follow-up of a danish case-study. BMC Health Serv. Res. 2018, 18, 365. [CrossRef] 